\title{
Solitary purpuric plaque: clinical and dermoscopic evolution of lichen aureus
}

\section{Asmae Rasso, Jihane Ziani, Sara Oukarfi, Hanane Baybay, Sara Elloudi, Fatima Zahra Mernissi}

Department of Dermatology CHU Hassan II, Fez, Morocco

Corresponding author: Dr. Asmae Rasso, E-mail: rassoasmae@gmail.com

\begin{abstract}
Lichen aureus is a pigmented purpuric dermatosis that typically presents with the acute onset of a solitary, unilateral, purple to rust-yel- low colored lichenoid patch or plaque on lower extremitiesl. We presented a 53-year-old woman consulted for the management of asymptomatic lesions. The dermatological examination revealed a purpuric infiltrated placard on the anterior surface of the left leg, dermoscopy and skin biopsy confirmed diagnostic of lichen aureus. Lichen aureus is a rare entity whose diagnosis remains difficult from where the interest of the dermoscopy to retain the diagnosis.
\end{abstract}

Key words: Dermoscopy; Lichen aureus; Purpuric dermatosis

\section{INTRODUCTION}

Lichen aureus (LA) is a rare variant of persistent pigmented purpuric dermatitis (PPPD), and is characterized by the appearance of a solitary goldenyellow, lichenoid macule $[1,2]$. We report a clinical and demoscopic evolutionary aspect of lichen aureus in our patient.

\section{CASE REPORT}

A 53-year-old woman with a history of diabetes who had been on insulin for 10 years, consulted for the management of asymptomatic leg-level lesions that had been evolving for 3 months. The dermatological examination revealed a purpuric infiltrated placard on the anterior surface of the left leg (Fig. 1). Dermoscopy showed a red blood cells, with whitish linear streaks, and erythematous-purplish fundus (Figs. 2 and 3). The skin biopsy showed slightly increased number of superficial vascular plexus vessels in the dermis, associated with dense perivascular inflammatory sheaths consisting mainly of lymphocytes accompanied by certain histiocytes.in places lymphocyte penetration of the wall of the capillary vessels by lymphocytes but without parietal necrosis (Figs. 4-6). In places, a slight extravasation of red blood cells in the interstitium around the vessels. Doppler ultrasound of the vessels of the lower limbs revealed a mediacalcosis of the fibular artery. Blood chemistry and full blood count results were normal. Based on these findings, we made a diagnosis of segmental Lichen aureus. the patient was treated with topical corticosteroid with improvement. Three months after the purplish erythematous appearance is replaced by a coppery brown color, the dermoscopy revealed a copper-red pigmentation background, more red blood cells than white streaks (Fig. 3).

\section{DISCUSSION}

The segmental lichen aureus is a "tattoo" of hemosiderin resulting from an altered local venous return, clinically, we have macules, an erythematous or purpuric, unilateral, solitary plaque. And is characterized histopathologically by no alteration of the epidermis, a lichenoid lymphocytic infiltrate

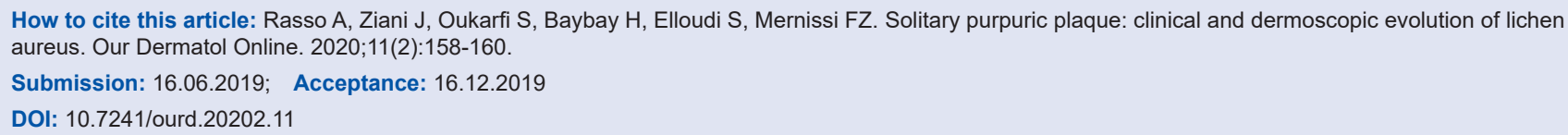




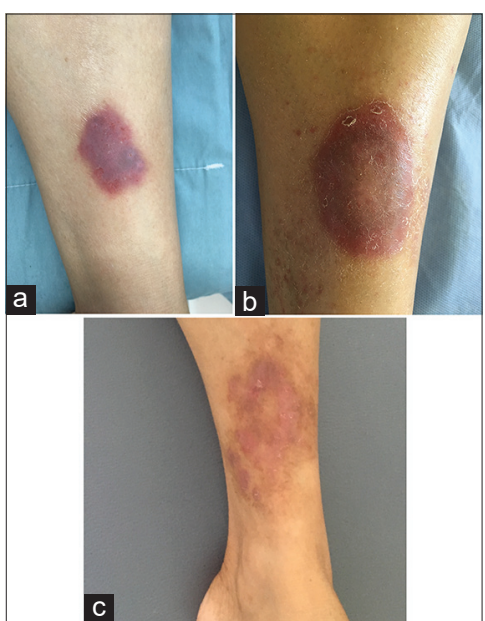

Figure 1: (a) The initial appearance of purpuric plaque. (B) After 3 mouths. (C) After 9 mouths.

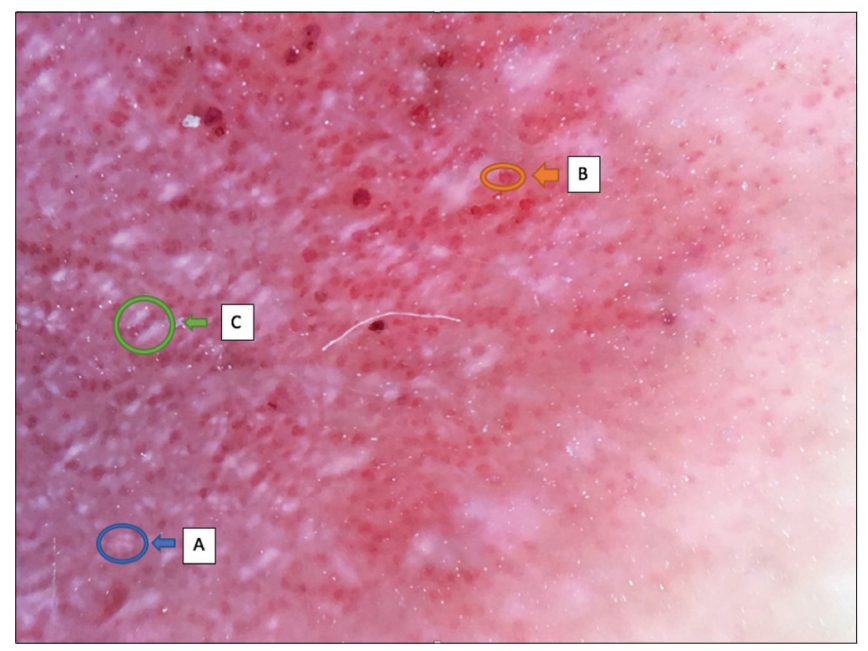

Figure 2: Dermoscopy of initial appearance with erythematous-purplish background; (A)rosette; (B) red blood cells; (C)whitish linear streaks.

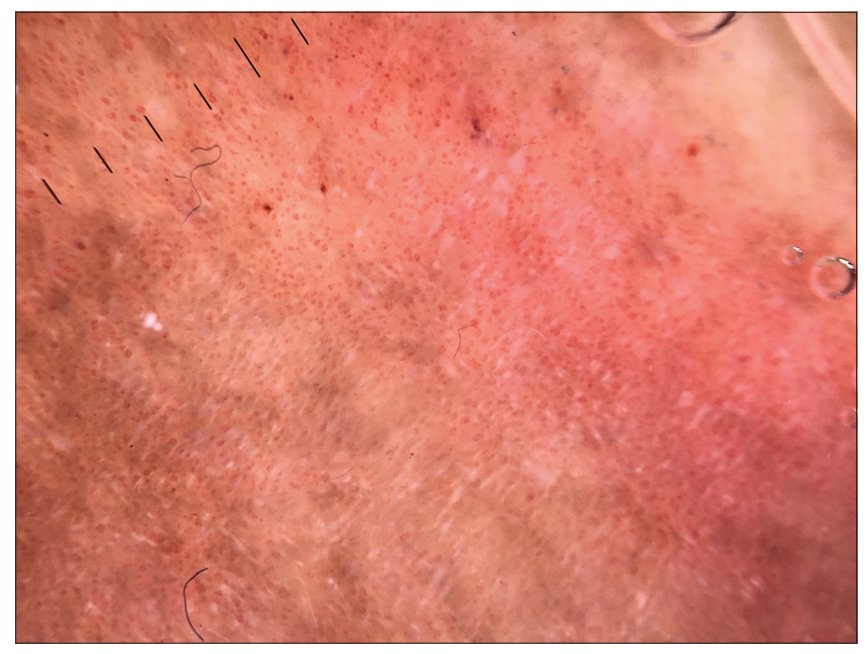

Figure 3: Dermoscopy of plaque after 3mouths showed a copper-red pigmentation background, more red blood cells than white streaks.

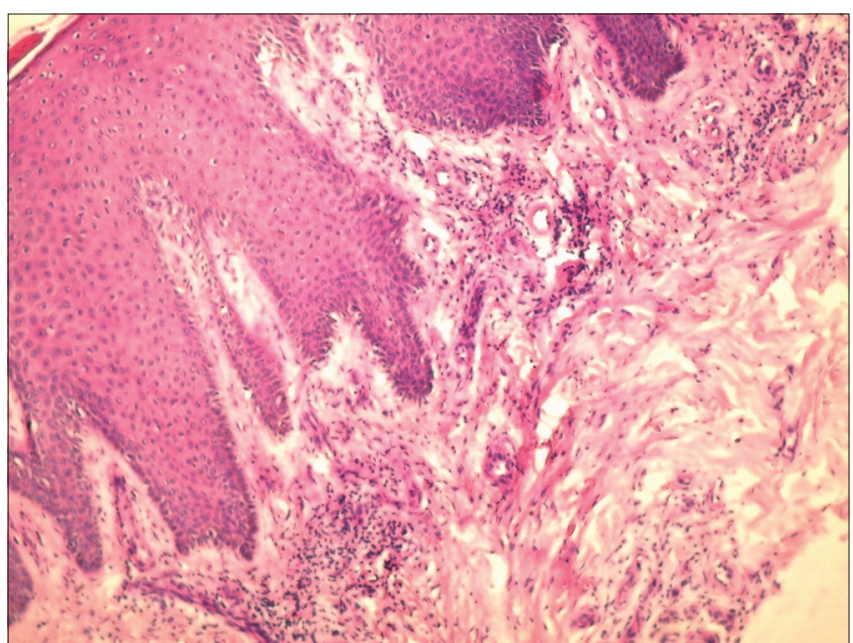

Figure 4: Coloration HES G x 100 -> Infiltrate inflammatory of the papillary and reticular dermis superficial and medium.

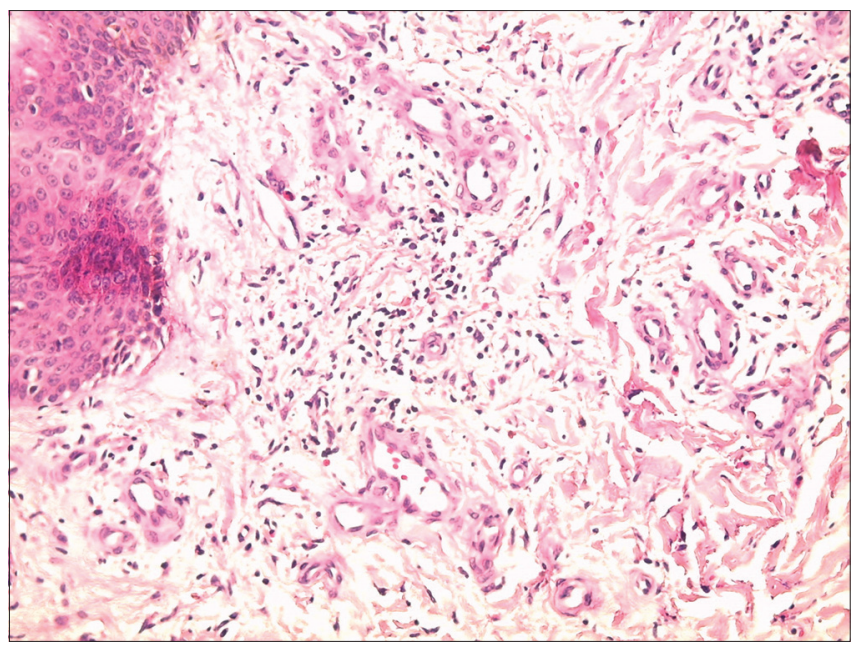

Figure 5: HES G x 200 staining -> Mononuclear inflammatory infiltrates perivascular + discrete extravasation of red blood cells.'

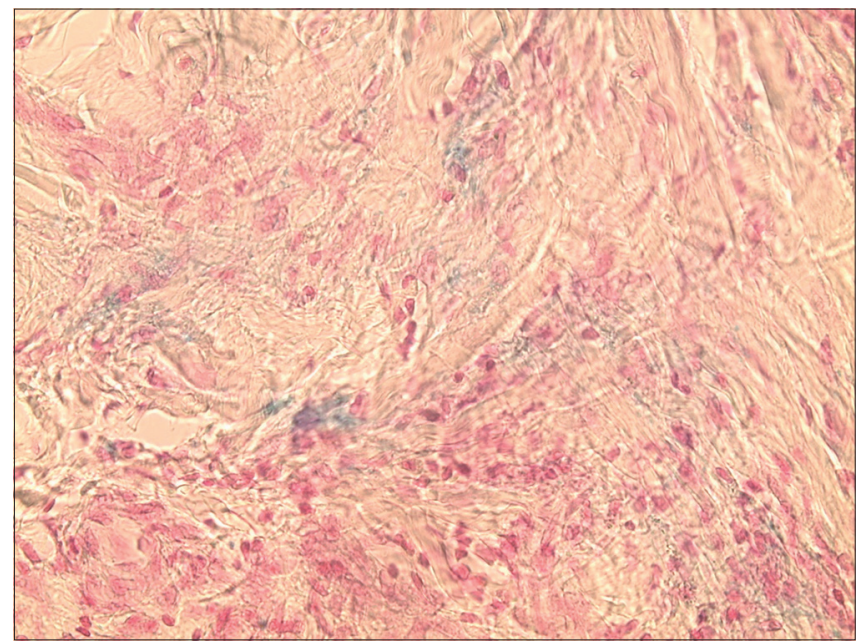

Figure 6: Perls G x 400 -> Perls positive heme deposits on the dermis. 
and extravasated erythrocytes and hemosiderin in the dermis. Dermatoscopy showed a copper-red pigmentation background, with brownish networks of interconnected lines and rounded to oval red blood cells [3]. Zeballos et al. reported that LA showed four characteristic dermoscopic features: (i) brownish or coppery-red diffuse background coloration; (ii) round to oval red dots, globules or patches; (iii) grey dots; and (iv) a network of brownish to grey interconnected lines [4]. The lesions usually persist for several years and then spontaneously disappear, the treatment is based on the dermocorticoid, puvatherapy. the patient treated by dermocorticoid with improvement.

\section{CONCLUSION}

clinical appearance of lichen aureus is variable, the dermoscopy is a less rapid non-invasive help to retain the diagnosis, as it allows to follow up as the case of our patient.

\section{Consent}

The examination of the patient was conducted according to the Declaration of Helsinki principles.

\section{REFERENCES}

1. Erreola AW Jauregui IE, López Zaldo JB, Huerta Rivera G, Soria Orozco M, Bonnafoux Alcaraz M. A case of lichen aureus successfully treated with $595 \mathrm{~nm}$ wavelength pulsed-dye laser. J Cosmet Dermatol. 2019;00:1-3.

2. Saito Y, Shimomura Y, Orime M, Kariya N, Abe R. Segmental lichen aureus in infancy. Clin Exp Dermatol. 2017;42:215-7.

3. Portela PS, Ormiga P, Carvalho de Freitas N. Dermoscopy of lichen aureus. An Bras Dermatol. 2013;88:253-5.

4. Zaballos P, Puig S, Malvehy J. Dermoscopy of pigmented purpuric dermatoses (lichen aureus): a useful tool for clinical diagnosis. Arch Dermatol. 2004;140:1290-1.

Copyright by Asmae Rasso, et al. This is an open-access article distributed under the terms of the Creative Commons Attribution License, which permits unrestricted use, distribution, and reproduction in any medium, provided the original author and source are credited. Source of Support: Nil, Conflict of Interest: None declared. 